\title{
A Systematic Review of the Health Economics of Pompe Disease
}

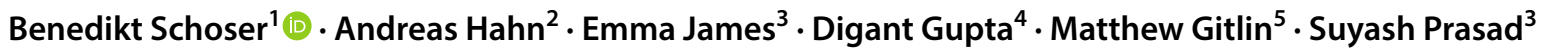

Published online: 2 May 2019

(c) The Author(s) 2019

\begin{abstract}
Background Pompe disease is a rare, severe neuromuscular disease with high mortality and substantial clinical and humanistic burden. However, the economic burden of Pompe disease and the health economic value of its treatments are not well understood. The objectives of this systematic review were to characterize the health economic evidence on Pompe disease, including healthcare resource use and costs (direct and indirect), health utilities, and the cost-effectiveness of current treatments used to manage patients with Pompe disease.

Methods A systematic search of MEDLINE ${ }^{\circledR}$ and Embase $^{\circledR}$ was performed to retrieve publications on the health economics of Pompe disease. Publications were screened according to predefined criteria, extracted, and quality assessed using the Newcastle-Ottawa Scale. Data were narratively synthesized.

Results Eight publications evaluated patients with infantile-onset Pompe disease (IOPD) (two studies), late-onset Pompe disease (LOPD) (four studies), or both (two studies). In IOPD, total cost of supportive therapy (excluding treatment) was $€ 32,871$ (equivalent to US $\$ 41,667$ when adjusted for currency and inflation to 2017 US dollars) over a life expectancy of 0.4 years. In adult LOPD, the average annual cost per patient of supportive therapy was $€ 22,475$ (adjusted $\$ 28,489$ ). Resource use in LOPD was high, with nursing home admissions accounting for $19 \%$ of annual direct medical costs. Health economic evaluations estimating incremental costs per quality-adjusted life year (QALY) gained with enzyme-replacement therapy (ERT) versus supportive therapy ranged from $£ 109,991$ (adjusted, $\$ 186,851$ ) per QALY gained in Columbia to $€ 1,043,868$ (adjusted, \$1,323,207) in the Netherlands.

Discussion Despite a full systematic literature search, only eight relevant publications were identified, most of which were of relatively poor quality. However, a significant economic burden of Pompe disease on patients, families, healthcare systems, and society was found, with the majority of costs driven by the only currently approved treatment, ERT. Health economic evaluations of ERT versus supportive therapy vary significantly, with the majority well above willingness-to-pay thresholds. New therapies and approaches to care are needed to address the persistent and lifelong economic burden of Pompe disease and the large incremental cost-effectiveness ratios observed.
\end{abstract}

Electronic supplementary material The online version of this article (https://doi.org/10.1007/s41669-019-0142-3) contains supplementary material, which is available to authorized users.

\section{Benedikt Schoser}

benedikt.schoser@med.uni-muenchen.de

1 Friedrich-Baur-Institut, Neurologische Klinik, Klinikum der Universität München, Ludwig-Maximilians-University Munich, Munich, Germany

2 Department of Child Neurology, University of Giessen, Feulgenstrasse 12, 35385 Giessen, Germany

3 Audentes Therapeutics, 600 California Street, Floor 17, San Francisco, CA 94108, USA

4 Bridge Medical Consulting Ltd, Gainsborough House, 2 Sheen Road, Richmond, London, UK

5 BluePath Solutions, 10951 West Pico Blvd, Suite 120, Los Angeles, CA 90064, USA

\section{Key Points for Decision Makers}

Pompe disease places a substantial economic burden on patients, families, healthcare systems, and society.

The majority of costs associated with the management of Pompe disease are driven by enzyme-replacement therapy (ERT), the only currently approved treatment.

The incremental cost-effectiveness ratio (incremental cost per quality-adjusted life-year gained) of ERT ranges widely, but is consistently high when compared with established cost-effectiveness thresholds. 


\section{Background}

By definition, rare diseases affect small numbers of individuals [no more than one in 2000 individuals in the European Union and one in 200,000 in the United States (US)] [1]. Costs per patient of treating rare diseases tend to be higher than those for more common conditions [2-4]. Pompe disease is a rare autosomal recessive, progressive, debilitating multisystemic neuromuscular disease in which acid $\alpha$-glucosidase (GAA) deficiency leads to intralysosomal accumulations of glycogen in all tissues. Based on age at manifestation and severity of disease, two main types of Pompe disease are distinguished. At one end of the spectrum, infantile-onset Pompe disease (IOPD) usually presents with hypertrophic cardiomyopathy and skeletal muscle weakness within the first 6 months of life. Without treatment, most patients die within the first year of life without achieving any motor milestone such as turning, sitting, or walking [5]. At the other end, the more slowly progressing late-onset Pompe disease (LOPD) can manifest any time, from early childhood to adulthood, as skeletal myopathy without major cardiac involvement, although survival is still adversely affected [6-8].

Because of its low prevalence (estimated at one in 138,000 to one in 14,000 [9-11], but most commonly quoted at one in 40,000 [12]), Pompe disease is classified as an orphan disease. Although not unique to orphan therapies, orphan conditions like Pompe disease have been chronically under researched prior to the approval of the first drug treatment, enzyme-replacement therapy (ERT) with recombinant human GAA (rhGAA) [13]. The first and only ERTs with rhGAA for Pompe disease-Myozyme and Lumizyme (alglucosidase alfa)—were launched in Europe and the US in 2006 and 2010, respectively. Until 2014, Lumizyme was available in the US only to LOPD patients, before being granted a US license for all Pompe patients in line with the rest of the world [14]. The introduction of ERT for the management of Pompe disease has improved the prognosis for patients by reducing the mortality, progression, and burden of this serious disorder. However, ERT is far from a cure, with mortality remaining at around 28-43\% in IOPD [15-18], and substantial morbidity persisting in most patients across the disease spectrum. Existing literature on the humanistic burden of Pompe disease suggests that beyond an initial improvement on first introduction of ERT, most patients have a quality of life that remains well below typical population norms, with certain symptoms, such as pain, being largely unaffected by ERT [19-25].

The overall economic burden of a chronic, progressive disease such as Pompe disease is established by evaluating the various components that contribute to the total cost of the disease. These components include direct medical costs (such as costs of treatment and medical devices), direct non-medical costs (including care in the home and transport), and indirect costs (including the costs of informal care, predominantly from parents, spouses and other family members, and productivity losses). Only when all of these elements are considered in total can the true economic burden of the condition to society be established.

Literature reviews have previously been published on the clinical or humanistic burden of Pompe disease [6-8, $25,26]$. However, relatively little attention has been paid to economic outcomes of the disease. The objectives of this systematic review were to characterize the health economic evidence on Pompe disease, including healthcare resource use and costs (direct and indirect), health utilities, and the cost-effectiveness of current treatments (incremental cost per quality-adjusted life year [QALY] gained) used to manage IOPD and LOPD patients.

\section{Methods}

No ethical approval was required because this study was a systematic review. A Preferred Reporting Items for Systematic Reviews and Meta-Analyses (PRISMA) checklist [27] and review protocol summary are provided as Electronic Supplementary Material.

\subsection{Search Strategy}

This review involved systematic searches in Embase ${ }^{\circledR} /$ MEDLINE ${ }^{\circledR}$ using Embase.com ${ }^{\circledR}$ to identify relevant articles published through end of December 2017 on the economic burden of Pompe disease. Each search was conducted using controlled vocabulary and key words and was limited to articles published in English and studies involving human subjects. The specific search terms used are provided as Electronic Supplementary Material. Search terms were selected to ensure a broad coverage of evidence types given the limited literature in the space and to identify economic evaluations that incorporated effectiveness evidence. To supplement the systematic searches, additional papers were identified through bibliography reviews of relevant articles and other web-based sources.

\subsection{Selection Criteria}

Titles and abstracts of articles identified were carefully screened by a single reviewer (DG) in the initial review for relevance to the topic. Articles were selected for inclusion based on predefined acceptance criteria, which included patient population (adults/children diagnosed with Pompe disease), outcome measures of interest (cost, healthcare 
resource use, health utilities, cost-effectiveness) and study design (quantitative and/or qualitative data collection). Articles exclusively reporting clinical and/or humanistic outcomes were excluded as not relevant. Other exclusion criteria included non-English language and absence of peer review for articles, editorials, correspondence, and conference abstracts.

Articles identified as potentially relevant were obtained in full text for further evaluation. Every full-text article was screened, and its eligibility was confirmed by at least two reviewers. Inconsistencies were resolved through consensus.

\subsection{Quality Assessment}

A descriptive analysis of each publication was conducted during the data extraction stage. The reviewers assessed each publication for quality by considering the characteristics that could introduce bias. All studies were given a quality rating using the Newcastle-Ottawa Scale [28], which grades studies from 1 (poorest quality) to 9 (highest quality). Details of the grading awarded to the different studies are available in the Electronic Supplementary Material.

\subsection{Data Extraction and Analysis}

Data from the included studies were extracted into a predefined extraction grid by a single reviewer (DG), and included study design, setting, patient characteristics, outcome measures, key results and conclusions. Given the descriptive nature of this systematic review, extracted data were narratively synthesized and reviewed by all authors.

To present the currencies used in a standardized format, all data were inflation- and currency-adjusted to 2017 United States dollars (USD) to provide clarity when comparing across studies (see Electronic Supplementary Material).

\section{Results}

\subsection{Overview}

Titles and abstracts of a total of 211 citations were screened following the initial searches, 16 of which were included for full-text screening. Eight articles were subsequently selected for final inclusion in this narrative synthesis (Fig. 1) [29-36]. Due to the substantial differences in patient characteristics and subsequent economic burden between IOPD and LOPD, these two phenotypes are considered separately in this review.

Two of the publications included were in IOPD patients only (in England/Colombia [29] and the Netherlands [30]), four were in patients with LOPD only (in the Netherlands [31, 32, 36] and Canada [33]), and two included both LOPD and IOPD patients (in the US [34] and England [35]). The two IOPD publications and one of the four LOPD publications were economic models that utilized data derived from published literature [29] or patient-level information that had not been previously presented $[30,36]$. The remaining publications were based on real-world data, mostly from two main registries: (1) the Dutch Erasmus Medical Center, an International Pompe Association (IPA) database; and (2) the National Collaborative Study of Lysosomal Storage Disorders, a multicenter, longitudinal, observational study in seven designated treatment centers in England.

Wyatt et al. presented cost data for children versus adults rather than for IOPD versus LOPD in England [35]. As it is not possible to separate the data according to phenotype, and as $85 \%$ of patients had LOPD, these data are described under the LOPD section (except for costs of ERT in IOPD, where data are presented for infants only). Data from the second mixed population study (conducted in the US) [34] are described in both the IOPD and LOPD discussions as appropriate.

An overview of the studies, including outcomes evaluated and quality ratings, is provided in Table 1 .

\subsection{Health Economic Evidence of IOPD}

\subsubsection{Management of IOPD is Associated with a Substantial Economic Burden}

In Pompe disease, the cost of purchasing and administering ERT dwarfs all other costs associated with the disease. As such, the costs of ERT are considered as a separate discussion. Here, we present costs of supportive care from an overall societal perspective from a single publication reporting a patient-simulation model based on data from 12 Dutch IOPD patients (average age at first measurement, 3.5 years) [30]. Using this model, total lifetime cost of an IOPD patient receiving supportive therapy only was $€ 32,871$ (currency and inflation-adjusted cost of $\$ 41,667$ ); however, the average mean life expectancy of patients estimated using the economic model was just 0.40 years. No other data on the costs of supportive care in IOPD were available.

\subsubsection{The Costs of Treating IOPD with ERT is Substantial}

Data relating to the costs of ERT in IOPD are found in four publications, of which two are based on modeled data and two on real-world data. The modeled data include the Kanters et al. (2014) publication in a Dutch population described in the preceding section [30] and a second publication reporting a deterministic Markov model based on annual cycles using published literature from a health system perspective over a 20-year time horizon in England and Colombia [29]. Real-world data are taken from a 
Fig. 1 Flowchart of screening and identification process. $I O P D$ infantile-onset Pompe disease, $L O P D$ late-onset Pompe disease. ${ }^{a}$ No meta-analysis was conducted in this review due to inadequate data

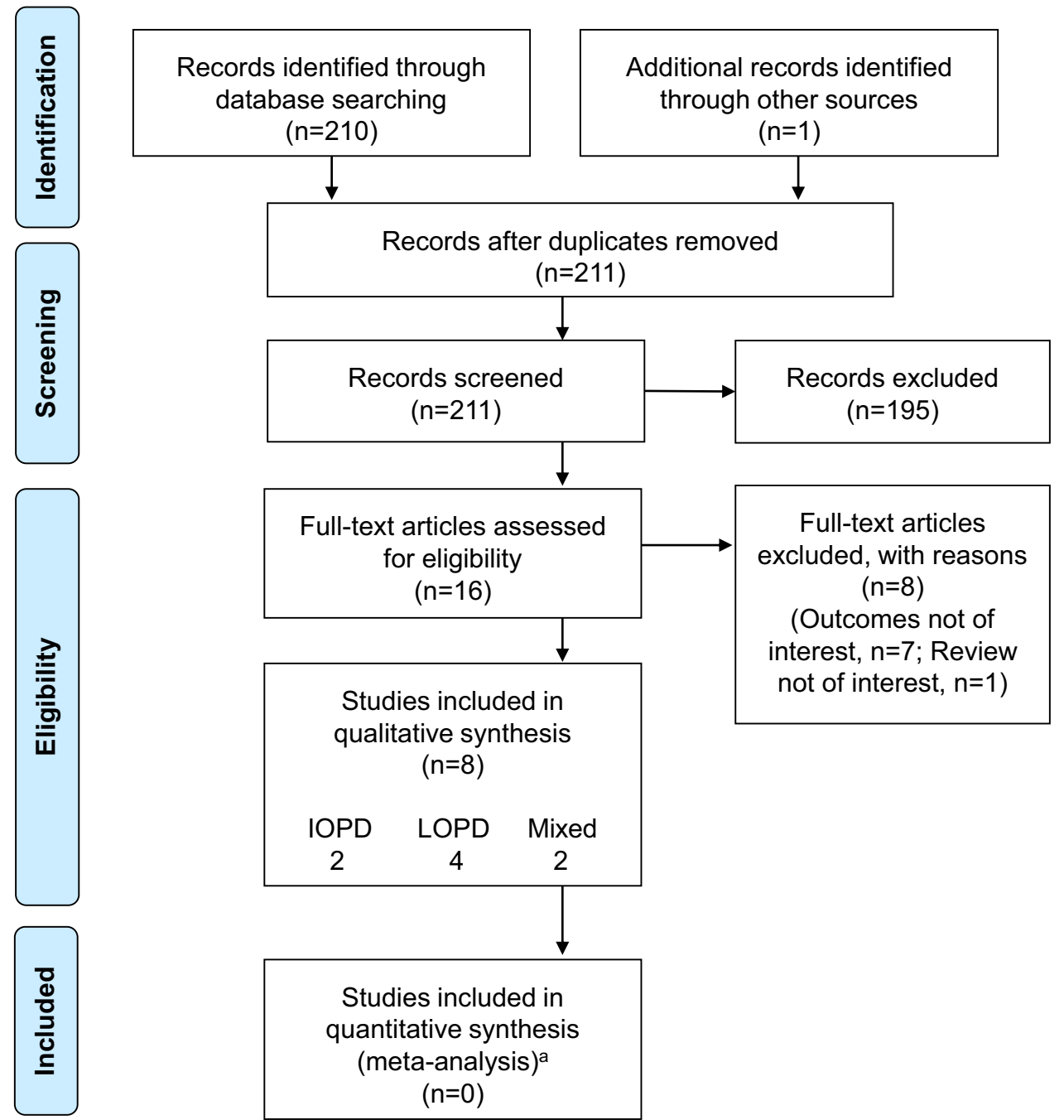

retrospective analysis of the national Medicaid pharmacy claims database, which describes drug utilization and spending trends in the US Medicaid program [34] and a United Kingdom (UK)-based cohort study in which 62 out of 65 LOPD patients and all IOPD patients $(n=12)$ received ERT [35]. In the latter study, the average time on ERT was 2.19 (range 0.15-9.7) years and 1.31 (range 0-3.12) years for IOPD and LOPD patients, respectively. This study reported cost data according to adult and child populations rather than by phenotype, and therefore cannot be separated into LOPD and IOPD patients.

Guo et al. [34] calculated US Medicaid quarterly prescriptions and reimbursement amounts for the first two ERTs available for Pompe disease: Myozyme and Lumizyme. Medicaid spending on Myozyme for IOPD was \$3.6 million in 2010. Prescriptions for Myozyme increased from one in quarter 2, 2006, to 127 in quarter 2, 2011, with an average price per prescription of approximately $\$ 10,000$. At $\$ 20,000$, the authors also noted that the price per prescription for Lumizyme (indicated for LOPD in the US) was essentially double the price for Myozyme (indicated for IOPD). This difference was thought to be caused by the higher dosages required for larger LOPD patients compared with smaller infants with IOPD.

In terms of per-patient costs, Fig. 2 provides a summary of the IOPD ERT costs from both modeled data and realworld data in the Netherlands, England, Colombia, and US, including standardization as it relates to currency and inflation from the data year to 2017 (the individual studies corrected for the increasing weight of the child due to growth over time within their own methodology). There is wide variability across studies, with annual inflation- and currency-adjusted ERT costing from $\$ 37,132$ for $20 \mathrm{mg} / \mathrm{kg}$ biweekly in the UK [35] to $\$ 207,604$ for $20 \mathrm{mg} / \mathrm{kg}$ biweekly in the US [34] and $\$ 152,372$ for $20 \mathrm{mg} / \mathrm{kg}$ biweekly in the Netherlands [30].

Castro-Jaramillo modeled the cost-effectiveness of ERT (Myozyme, $20 \mathrm{mg} / \mathrm{kg}$ ) given every 2 weeks to IOPD patients in England and Colombia [29]. Costs of the infusions and costs of managing complications from ERT application were 


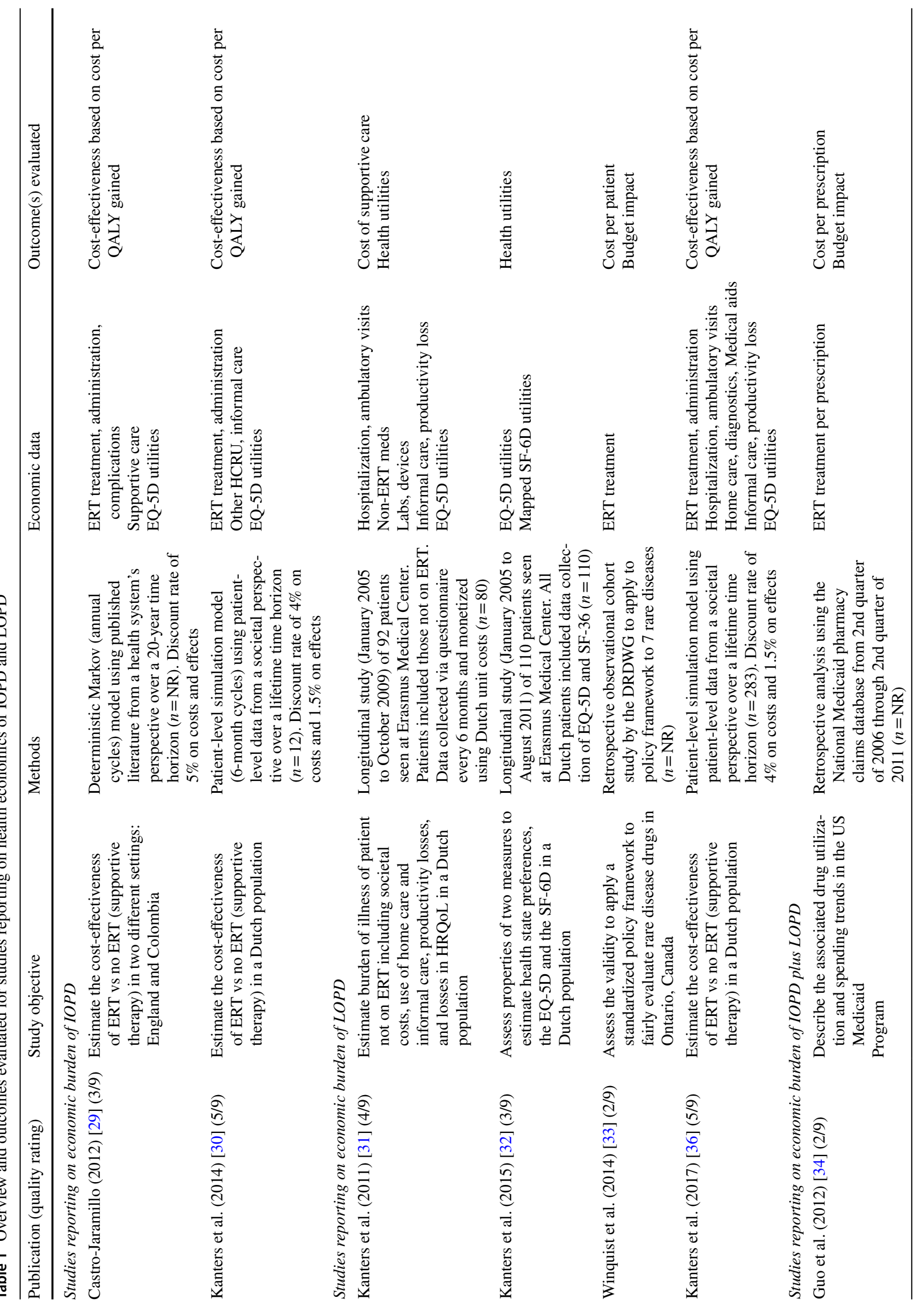


included in the model. In this model, total annual costs per patient (average weight, $10 \mathrm{~kg}$ ), including cost of ERT, were $£ 194,342$ (inflation- and currency-adjusted cost, \$287,870) in England compared with $£ 97,963$ (adjusted, \$166,418) in Colombia [29]. The largest component of cost in each case was use of the pediatric intensive care unit $(£ 148,200$ [adjusted, \$219,522] and $£ 49,351$ [adjusted, $\$ 83,837$ ] per patient for England and Colombia, respectively). ERT was the second largest cost component ( $£ 38,324$ [adjusted, $\$ 56,768$ ] and $£ 41,678$ [adjusted, $\$ 70,802$ ] per patient for England and Colombia, respectively). The total lifetime cost from the cost-effectiveness analysis for the ERT arm was $£ 1,337,118$ (adjusted, $\$ 1,980,613$ ) in England compared with $£ 607,329$ (adjusted, $\$ 1,031,719$ ) in Colombia.

Kanters et al. (2014) modeled the total and incremental costs for ERT versus supportive care in IOPD in the Netherlands [30]. Total costs for patients treated with ERT were calculated based on four components: (1) cost of drug; (2) infusion-related costs; (3) costs related to other healthcare use; and (4) informal care costs. Patients receiving supportive therapy did not incur costs of the drug and infusion-related costs. Total lifetime cost was $€ 7,032,899$ (inflation- and currency-adjusted cost, $\$ 8,914,905$ ) for ERT-treated patients, which represents an incremental lifetime cost of $€ 7,000,028$ (95\% confidence interval [CI] 1,869,635-12,130,422) (adjusted, \$8,873,238 [95\% CI $2,369,950-15,376,527])$ over supportive care alone. The majority (95\%) of this was due to the specific costs of ERT and its infusion ( $€ 6,630,525$ [adjusted, $\$ 8,404,856$ ] and $€ 212,793$ [adjusted, \$269,736], respectively). The increment for other costs (medical costs plus costs of informal care) was $€ 156,711$ (95\% CI 131,728-181,694) (adjusted, $\$ 198,647$ [95\% CI 166,978-230,315]). It should be noted that the higher costs incurred by ERT-treated IOPD patients versus those treated with supportive therapy were not due solely to the ERT treatment, but also because they lived much longer (life expectancy of 13.79 years vs 0.4 years for the supportive treatment group).

\subsubsection{Cost-Effectiveness of ERT in IOPD}

The patient-simulation model described by Kanters et al. (2014) from the Netherlands also estimated the incremental costs per QALY at a dosage of $40 \mathrm{mg} / \mathrm{kg} / \mathrm{week}$ (regimen used in some centers for IOPD) and $20 \mathrm{mg} / \mathrm{kg}$ biweekly (licensed dose) compared with supportive care alone [30]. At $40 \mathrm{mg} / \mathrm{kg} /$ week, the incremental cost per QALY was estimated to be $€ 1.04$ million ( $€ 7$ million incremental costs and 6.75 incremental QALYs) and the incremental cost per life year gained was $€ 0.5$ million ( $€ 7$ million incremental costs and 13.39 incremental life years); total costs were considerably lower in the $20 \mathrm{mg} / \mathrm{kg}$ biweekly analysis (Table 2). The incremental cost-effectiveness ratios (ICERs) at the 


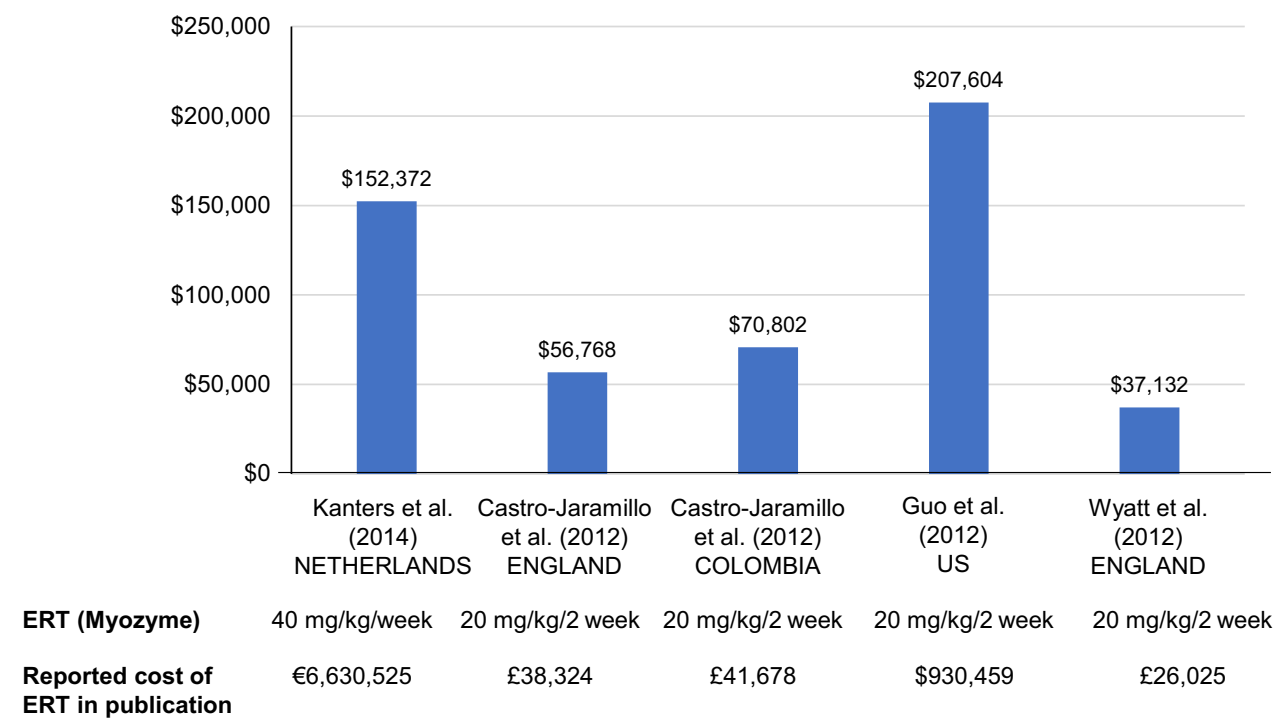

Fig. 2 Annual total ERT costs per patient (IOPD; annual currencyand inflation-adjusted [2017 USD]) ${ }^{\mathrm{a}}$. CPI consumer price index, ERT enzyme-replacement therapy, IOPD infantile-onset Pompe disease, $O E C D$ Organisation for Economic Cooperation and Development,

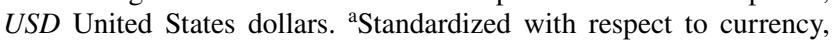
costs, and dose $(20 \mathrm{mg} / \mathrm{kg} / 2$ week). Total ERT costs represent drug acquisition cost only. These costs exclude infusion, supportive care, and other costs associated with ERT for Pompe disease. Annual cost is calculated based on total costs divided by total time alive for all studies except Guo et al. 2012. Annual costs were estimated based on costs and prescriptions dispensed per quarter (prescriptions adjusted to patients based on an assumed regimen of $20 \mathrm{mg} / \mathrm{kg} / 2$ weeks) to estimate an annual per-patient cost. Annual cost for $20 \mathrm{mg} / \mathrm{kg}$ every
2 weeks per patient calculated as $€ 120,205$ [32], £38,324 (CastroJaramillo 2012 - England), £41,678 (Castro-Jaramillo 2012-Colombia), $\$ 190,488$ [36], and $£ 26,025$ [37]. Inflation-adjusted from data to year 2017 (inflation-adjusted to 2017 using average annual inflation rate per year reported by the OECD for each country and inflated based on data year) calculated as $€ 135,215$ [32], £44,109 (CastroJaramillo 2012-England), £50,013 (Castro-Jaramillo 2012-Colombia), \$207,604 [36], and £28,852 [37]. OECD (2018), "Inflation consumer price index (CPI) (indicator)." https://doi.org/10.1787/eee82 e6e-en (Accessed on $17 \mathrm{Jul}$ 2018). Inflation-adjusted currency converted to USD based on currency reported in the publication. OECD (2018), "Exchange rates (indicator)." https://doi.org/10.1787/037ed 317-en (Accessed on 17 Jul 2018)

Table 2 Incremental cost-effectiveness ratios of ERT in IOPD including inflation and currency adjustment

\begin{tabular}{|c|c|c|c|c|c|c|}
\hline Author, year & Currency & Country & $\begin{array}{l}\text { Treatment } \\
\text { (Myozyme) }\end{array}$ & ICER & $\begin{array}{l}\text { Inflation-adjusted } \\
\text { from data year to } \\
2017^{a}\end{array}$ & $\begin{array}{l}\text { Currency and inflation- } \\
\text { adjusted (2017 USD) }\end{array}$ \\
\hline $\begin{array}{l}\text { Kanters et al. (2014) } \\
\text { [30] }\end{array}$ & 2009 euros & Netherlands & $40 \mathrm{mg} / \mathrm{kg} /$ week & $\begin{array}{l}€ 1,043,868 \text { per } \\
\text { QALY gained }\end{array}$ & $€ 1,174,210$ & $\$ 1,323,207$ \\
\hline $\begin{array}{l}\text { Kanters et al. (2014) } \\
\text { [30] }\end{array}$ & 2009 euros & Netherlands & $20 \mathrm{mg} / \mathrm{kg} / 2$ week & $\begin{array}{l}€ 286,114 \text { per QALY } \\
\text { gained }\end{array}$ & $€ 321,840$ & $\$ 362,678$ \\
\hline $\begin{array}{l}\text { Castro-Jaramillo } \\
\text { (2012) [29] }\end{array}$ & $2010 \mathrm{GBP}$ & England & $20 \mathrm{mg} / \mathrm{kg} / 2$ week & $\begin{array}{l}£ 234,308 \text { per QALY } \\
\text { gained }\end{array}$ & $£ 269,674$ & $\$ 347,070$ \\
\hline $\begin{array}{l}\text { Castro-Jaramillo } \\
\text { (2012) [29] }\end{array}$ & 2010 GBP & Columbia & $20 \mathrm{mg} / \mathrm{kg} / 2$ week & $\begin{array}{l}£ 109,991 \text { per QALY } \\
\text { gained }\end{array}$ & $£ 145,183$ & $\$ 186,851$ \\
\hline
\end{tabular}

$C P I$ consumer price index, ERT enzyme-replacement therapy, GBP Great Britain pounds, ICER incremental cost-effectiveness ratio, IOPD infantile-onset Pompe disease, $O E C D$ Organisation for Economic Cooperation and Development, $Q A L Y$ quality-adjusted life year, USD United States dollars

${ }^{a}$ Inflation-adjusted from data to year 2017 (inflation-adjusted to 2017 using average annual inflation rate per year reported by the OECD for each country and inflated based on data year). OECD (2018), "Inflation consumer price index (CPI) (indicator)." https://doi.org/10.1787/eee82 e6e-en (accessed on 17 July 2018). Inflation-adjusted currency converted to USD based on currency reported in the publication. OECD (2018), "Exchange rates (indicator)." https://doi.org/10.1787/037ed317-en (accessed on 17 July 2018)

$20 \mathrm{mg} / \mathrm{kg}$ biweekly dose were approximately 3.6 times lower (€286,114 [inflation- and currency-adjusted cost, \$362,678]) than the base case ICER ( $40 \mathrm{mg} / \mathrm{kg} /$ week). The fact that physicians are increasingly preferring a $40 \mathrm{mg} / \mathrm{kg}$ biweekly, or even weekly, dosing regimen, adds considerably to the cost burden. However, it should be noted that clinical outcomes are generally improved at higher doses, creating the possibility of changes in QALY and/or life expectancy. 
As described in Sect. 3.2.2, the cost-effectiveness of ERT (Myozyme, $20 \mathrm{mg} / \mathrm{kg}$ ) given every 2 weeks to IOPD patients was modeled in England and Colombia [29]. In this study, the ICER per QALY gained was $£ 234,308(\sim £ 1,187,940$ incremental costs and 5.07 incremental QALYs) for England and $£ 109,991(\sim 557,653$ incremental costs and 5.07 incremental QALYs) for Colombia [29] (Table 2). The authors noted that ICERs per QALY were very high in both cases, compared with 'established' cost-effectiveness thresholds per QALY or year of life gained used in some other countries for decision making [37].

For instance, in England, National Institute for Health and Care Excellence (NICE) decisions appear to have been based on a cost-effectiveness threshold upwards of $£ 20,000-£ 30,000 / Q A L Y$ [38]. In the US, the cost-effectiveness threshold can range from $\$ 100,000$ to $\$ 150,000$ for cancer drugs and $\$ 50,000$ to $\$ 100,000$ for noncancer drugs [39]. It should be noted that the time horizons for all three cost-effectiveness analyses were set to lifetime, but differences in discounting may have a significant impact on assessing results across different cost-effectiveness analyses. For example, Kanters et al. (2014) utilized recommendations set forth in the Dutch pharmacoeconomic guidelines assuming an annual discount of $4 \%$ for costs and $1.5 \%$ for effectiveness [30], while Castro-Jaramillo assumed 5\% annual discounting for both costs and effectiveness when estimating ICERs for England and Columbia [29]. The resulting differences in incremental costs are due to differences in treatment and medical costs inputs between countries, while the differences in incremental QALYs reported (Kanters et al. [2014] 6.75 years vs 5.07 in Castro-Jaramillo) are the result of differences in health utility inputs and of discounting of effectiveness over the lifetime horizon.

\subsection{Health Economic Evidence of LOPD}

\subsubsection{LOPD is Associated with a Substantial Economic Burden}

Data relating to the economic burden of LOPD (excluding ERT costs) are taken from two real-world publications; the first was a retrospective cohort study conducted in the Netherlands in 80 adult LOPD patients with mild-to-severe disease receiving supportive care only [31], and the second was the UK-based cohort study described previously [35]. The cost of ERT in LOPD is considered in the subsequent section.

Table 3 provides a summary of the costs reported in the two studies, including adjustment for inflation and currency. It is interesting to note that when the costs from the papers are standardized, there remains a substantial difference in overall annual costs (ranging from $\$ 8989$ for an adult and $\$ 14,382$ for a child in Wyatt et al. [35] to $\$ 28,489$ in
Kanters et al. [2011] [31]). This can largely be attributed to the absence of costs associated with informal care and productivity losses in the analysis by Wyatt et al. However, even comparing direct medical costs between the two studies, the standardized figure of $\$ 17,340$ calculated from Kanters et al. (2011) [31] exceeds the corresponding value of $\$ 14,301$ for adults, and is considerably higher than the figure of $\$ 6422$ calculated for children from the Wyatt study [35]. These differences are purely due to differences in the cost of care, and are not explained by the type of service, currency, or data year. As well as the obvious differences in treatment costs between adults and children, these differences may be explained by the fact that the inflation- and currency-adjusted figures disregard differences in purchasing power and healthcare systems in different countries as well as inconsistencies in patient characteristics and reporting.

Total estimated inflation- and currency-adjusted costs for each LOPD patient receiving supportive care in the Netherlands were $\$ 28,489$ per year (range, $\$ 0-\$ 214,908$ ) [31]. Direct medical costs (defined as hospital days, intensive care, nursing home, ambulatory care, medication and other medical costs including tests, procedures, respiratory support, and medical devices) accounted for the majority $(61 \%)$ of the total estimated costs $(\$ 17,340$ per patient per year) in LOPD. Non-medical direct costs (transportation and other non-medical care) accounted for $2 \%$ of the total cost (\$534), while indirect costs (informal care and productivity losses) totaled $\$ 7838$ (37\%). In terms of healthcare resources used by adult LOPD patients receiving supportive care, Kanters et al. (2011) reported that patients averaged two visits to the general practitioner (GP) per year and five outpatient hospital visits, most commonly to a neurologist (28\%) [31]. In summary, almost half of the estimated mean annual total health and social care cost per adult (excluding ERT) was attributed to NHS hospital services ( $\$ 4280$ of total cost of \$8989), while among children, NHS hospital services accounted for $92 \%$ of total health and social-care costs $(\$ 13,269$ of total cost of $\$ 14,382)$ [35].

As well as direct costs of care, indirect economic costs must also be considered in relation to the overall economic burden of a disease. Indirect economic burden has two major components: costs of informal care (predominantly from spouses and other family members) and productivity losses. Kanters et al. (2011) reported that $85 \%$ of patients in the Netherlands received informal care, usually from more than one caregiver, suggesting a significant impact on the patient's social network [31]. The total cost of the informal care was estimated at $€ 5741$ annually (range, $€ 0-36,037$ ) (inflation- and currency-adjusted cost, $\$ 7277$ [range, $\$ 0-45,681])$, accounting for $26 \%$ of the total annual costs of $€ 22,475$.

In terms of productivity losses, Kanters et al. (2011) reported that only 31 of 80 patients (39\%) were employed, 
Table 3 Studies reporting supportive care costs in LOPD patients, including inflation and currency adjustment

\begin{tabular}{|c|c|c|c|c|c|c|}
\hline Author, year & Currency & Country & Costs included & $\begin{array}{l}\text { Reported mean } \\
\text { annual costs }\end{array}$ & $\begin{array}{l}\text { Inflation-adjusted } \\
\text { mean annual costs } \\
\text { from data year to } \\
2017^{\text {a }}\end{array}$ & $\begin{array}{l}\text { Currency and inflation- } \\
\text { adjusted mean annual } \\
\text { costs (2017 USD) })^{\mathrm{a}}\end{array}$ \\
\hline $\begin{array}{l}\text { Kanters et al. (2011) } \\
{[31]^{\mathrm{b}}}\end{array}$ & 2009 euros & Netherlands & $\begin{array}{l}\text { Medical: Hospital } \\
\text { days, ICU, nursing } \\
\text { home, ambulatory } \\
\text { care, home care, } \\
\text { medication, tests, } \\
\text { procedures, devices } \\
\text { Direct non-medical: } \\
\text { Transportation, } \\
\text { other non-medical } \\
\text { costs } \\
\text { Indirect: informal } \\
\text { care, productivity } \\
\text { losses }\end{array}$ & $\begin{array}{l}\text { Overall: } € 22,475 \\
\text { Direct medical: } \\
€ 13,679 \\
\text { Direct non-medical: } \\
\quad € 421 \\
\text { Indirect: } € 8374\end{array}$ & $\begin{array}{l}\text { Overall: } € 25,281 \\
\text { Direct medical: } \\
€ 15,387 \\
\text { Overall indirect: } \\
€ 9420 \\
\text { Indirect (no produc- } \\
\text { tivity): } € 6955\end{array}$ & $\begin{array}{l}\text { Overall: } \$ 28,489 \\
\text { Direct medical: } \\
\$ 17,340 \\
\text { Overall indirect: } \\
\$ 10,615 \\
\text { Indirect (no productiv- } \\
\text { ity): } \$ 7838\end{array}$ \\
\hline $\begin{array}{l}\text { Wyatt et al. (2012) } \\
\text { (adult) [35] }\end{array}$ & 2011 GBP & UK & $\begin{array}{l}\text { Medical: Hospital } \\
\text { days, outpatient vis- } \\
\text { its, day cases, acci- } \\
\text { dent and ED visits, } \\
\text { GP visits, nurse } \\
\text { visits, therapists } \\
\text { Direct non-medical: } \\
\text { Social workers, } \\
\text { home help, care } \\
\text { attendant, commu- } \\
\text { nity support worker, } \\
\text { housing worker }\end{array}$ & $\begin{array}{l}\text { Overall: } £ 6300 \\
\text { Direct medical: } \\
£ 4501 \\
\text { Direct non-medical: } \\
£ 1799\end{array}$ & $\begin{array}{l}\text { Overall: } £ 6984 \\
\text { Direct medical: } \\
£ 4990 \\
\text { Overall indirect: } \\
£ 1994\end{array}$ & $\begin{array}{l}\text { Overall: } \$ 8989 \\
\text { Direct medical: } \$ 6422 \\
\text { Overall indirect: } \$ 2567\end{array}$ \\
\hline $\begin{array}{l}\text { Wyatt et al. (2012) } \\
\text { (child) [35] }\end{array}$ & 2011 GBP & UK & $\begin{array}{l}\text { Medical: Hospital } \\
\text { days, outpatient vis- } \\
\text { its, day cases, acci- } \\
\text { dent and ED visits, } \\
\text { GP visits, nurse } \\
\text { visits, therapists } \\
\text { Direct non-medical: } \\
\text { Social workers, } \\
\text { home help, care } \\
\text { attendant, commu- } \\
\text { nity support worker, } \\
\text { housing worker }\end{array}$ & $\begin{array}{l}\text { Overall: } £ 10,080 \\
\text { Direct medical: } \\
£ 10,023 \\
\text { Direct non-medical: } \\
£ 57\end{array}$ & $\begin{array}{l}\text { Overall: } £ 11,175 \\
\text { Direct medical: } \\
\quad £ 11,112 \\
\text { Overall indirect: } £ 63\end{array}$ & $\begin{array}{l}\text { Overall: } \$ 14,382 \\
\text { Direct medical: } \\
\quad \$ 14,301 \\
\text { Overall indirect: } \$ 81\end{array}$ \\
\hline
\end{tabular}

$C P I$ consumer price index, $E D$ Emergency department, $G B P$ Great Britain pounds, $G P$ general practitioner, $I C U$ intensive care unit, $L O P D$ lateonset Pompe disease, OECD Organisation for Economic Cooperation and Development, USD United States dollars

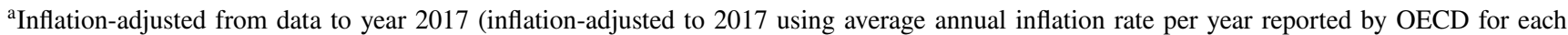
country and inflated based on data year). OECD (2018), "Inflation consumer price index (CPI) (indicator)." https://doi.org/10.1787/eee82e6een (accessed on 17 July 2018). Inflation-adjusted currency converted to USD based on currency reported in the publication. OECD (2018), "Exchange rates (indicator)." https://doi.org/10.1787/037ed317-en (Accessed on 17 July 2018)

${ }^{\mathrm{b}}$ Individual reported mean annual costs for Kanters et al. (2011) [31] do not exactly sum to the overall cost due to rounding

with 32 patients (40\%) indicating that they had stopped working due to Pompe disease [31]. Of those patients who were working, $32 \%$ were reported absent from work due to illness for an average of 12 work days per year. Productivity losses were estimated at $€ 2633$ (range, $€ 0-38,176$ ) per patient per year (inflation- and currency-adjusted cost, \$3338 [range, \$0-48,392]), which accounted for $12 \%$ of total annual disease-related costs [31].

\subsubsection{Costs of ERT in LOPD are Substantial}

Real-world data on the costs of ERT in LOPD are taken from four studies conducted in the US [34], England [35], Canada [33], and the Netherlands [36]. Figure 3 provides a summary of these cost studies, including standardization across identified studies as it related to the currency and inflation from the data year to 2017 . The data were relatively homogeneous, with adjusted annual costs of ERT for 


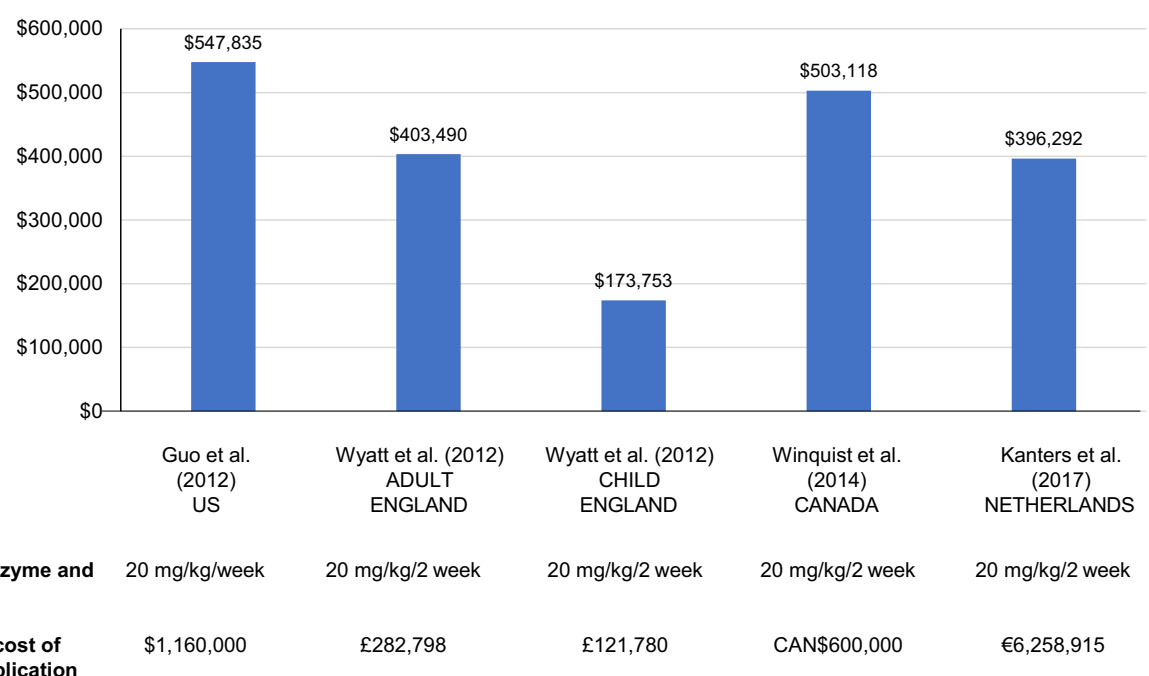

Fig. 3 Annual total ERT costs per patient (LOPD; annual currency- and inflation-adjusted [2017 USD]) $)^{\mathrm{a}}$. CAN\$ Canadian dollar, $E R T$ enzyme-replacement therapy, $L O P D$ late-onset Pompe disease, $O E C D$ Organisation for Economic Cooperation and Development, USD United States dollars. ${ }^{\text {aT }}$ Total ERT costs represent drug acquisition cost only. These costs exclude infusion, supportive care, and other costs associated with ERT for Pompe disease. Annual cost is calculated based on total costs divided by total time alive for Wyatt et al. 2012. Annual costs for Guo et al. 2012 were estimated based on costs and prescriptions dispensed per quarter (prescriptions adjusted to patients based on an assumed regimen of $20 \mathrm{mg} /$

$20 \mathrm{mg} / \mathrm{kg}$ biweekly ranging from $\$ 503,118$ [33] to $\$ 547,835$ [34] for patients classified as having LOPD, and $\$ 173,753$ to $\$ 403,490$ for patients classified as children or adults, respectively [35]. Overall lifetime costs for LOPD were not reported in any of the publications.

Winquist et al. [33] conducted a retrospective observational cohort study as part of a Canadian policy framework intended to evaluate the public funding of drugs for rare diseases. They reported the cost of ERT as $\$ 840$ per 50-mg vial, which was calculated to be equivalent to $\$ 600,000$ annually for an LOPD patient weighing $70 \mathrm{~kg}$, leading to a total drug expenditure of $\$ 16,861,408$ between June 2009 and June 2012.

As described previously, Wyatt et al. [35] reported the annual cost of caring for people with Pompe disease in England, excluding the purchase cost of ERT, at an estimated $£ 6300$ for an adult and $£ 10,080$ for a child. In comparison, the mean annual cost of ERT was substantially greater at $£ 282,798$ for adults and $£ 121,780$ for children with Pompe disease. These findings confirm that the cost of the ERT itself dominates all other costs associated with LOPD.

Guo et al. reported that Lumizyme prescriptions in the US increased from six in quarter 3,2010 , to 60 in quarter 2, 2011, and expenditures rose from $\$ 119,691$ to $\$ 1.16$ million during the same period [34]. The average price per $\mathrm{kg} / 2$ weeks) to estimate an annual per patient cost. Annual costs were reported directly from Winquist et al. 2014. Annual cost for $20 \mathrm{mg} /$ $\mathrm{kg}$ every 2 weeks per patient calculated as $\$ 502,667$ [36], £282,798 (adult [37]), £121,780 (child [37]), and CAN\$600,000 [35]. Inflationadjusted from data to year 2017 (inflation-adjusted to 2017 using average annual inflation rate per year reported by the OECD for each country and inflated based on data year) calculated as $\$ 547,835$ [36], $£ 313,513$ (adult [37]), $£ 135,007$ (child [37]), and CAN\$652,915 [35]. Inflation-adjusted currency converted to USD based on currency reported in the publication. OECD (2018), "Exchange rates (indicator)." https://doi.org/10.1787/037ed317-en (accessed on 17 July 2018)

prescription was approximately $\$ 20,000$, and in the first two quarters of 2011, Medicaid spending for Lumizyme totaled \$1.8 million [34].

\subsubsection{Patients with LOPD Tend to Have Low Health Utilities Versus the Normal Population}

Real-world data on health utilities among LOPD patients measured using the EuroQoL-5D (EQ-5D) (version not specified) or Short Form-6D (SF-6D) scales are taken from Kanters et al. (2011) [31] (Dutch patients receiving only supportive care) and Kanters et al. (2015) [32] (Dutch patients treated with ERT) using Dutch tariffs.

Kanters et al. (2011) reported an overall health utility score of 0.72 (standard deviation [SD], 0.18; range, 0.17-1.00) among untreated LOPD patients, as measured using the EQ-5D [31]. This is $17 \%$ lower than the utility score of the Dutch population as a whole (previously estimated at 0.87 [40]). At 0.15 , the utility decrement arising from Pompe disease was statistically significant, and was ascribed predominantly to mild limitations in the domains of mobility, usual activities, and pain. The authors cautioned, however, that large variations in disease severity may undermine comparisons of health utilities between different diseases. In addition, patients with severe limitations were only 
observed in a small number of cases included in this analysis; as such, the impact on health utilities of Pompe disease from patients across the spectrum of disease severity may be underestimated.

Both EQ-5D and SF-6D among LOPD patients receiving ERT were evaluated by Kanters et al. (2015) [32]. Mean (SD) EQ-5D and SF-6D utility scores were reported to be $0.670(0.201)$ and $0.699(0.092)$, respectively. The authors reported that the maximum utility score of 1 was achieved in $6 \%$ of the EQ-5D observations, but was not observed in any patients on the SF-6D scale. In addition, the lowest possible score ( -0.35 for EQ-5D and 0.291 for SF-6D) was not observed in either instrument among these patients.

\subsubsection{Cost-Effectiveness of ERT in LOPD}

Data on the cost-effectiveness of ERT can be drawn from a simulation model using Dutch patient-level data from a societal perspective over a lifetime horizon published by Kanters et al. (2017) [36]. This study modeled two scenarios: a conservative approach that assumed no effects of ERT on survival after the observed period (scenario 1) and a projected approach in which the effect of ERT on survival was extrapolated beyond the observation period by carrying forward the estimated treatment-specific survival probabilities at the end of the observation period (scenario 2). In this analysis, the ICERs were lower in scenario 2 ( $€ 1.4$ million [inflationand currency-adjusted, $\$ 1,602,570$ ] per life year gained and $€ 1.8$ million [adjusted, $\$ 2,045,855$ ] per incremental QALY for scenario 2 vs $€ 3.4$ million [adjusted, \$3,940,590]) per life year gained and $€ 3.2$ [adjusted, $\$ 3,652,575$ ] per incremental QALY for scenario 1).

\section{Discussion}

\subsection{Overview}

Pompe disease can have devastating consequences for both patients and their families. The clinical and humanistic burden of Pompe disease has been reviewed elsewhere [4-8, $25,26]$; however, to date, no systematic review on the health economic evidence of Pompe disease has been published. Here, we present the findings from eight published papers, and describe systematically the economic burden in both LOPD and IOPD.

As described elsewhere, the impact of Pompe disease on quality of life is substantial. Within an economic framework, this review shows the overall utility score to range from 0.67 to $0.72[31,32]$. This compares with an average utility score of 0.87 in the Dutch population as a whole, showing that Pompe disease patients have a utility deficit of $>0.1$ on a scale that is commonly (not always) scored from 0 to 1 , and represents a potentially clinically meaningful preference to avoid the humanistic burden associated with this disease.

The data included here confirm the substantial economic burden associated with both LOPD and IOPD, despite the relatively small numbers of patients affected. In terms of IOPD, the total lifetime cost of receiving supportive therapy only was estimated to be $€ 32,871(\$ 41,667)$ [30], over a life expectancy of 0.4 years. Among adult LOPD patients receiving supportive care only, the average annual total cost for each patient was reported to be $€ 22,475$ (currency- and inflation-adjusted [2017] equivalent; \$28,489) [31]. The largest cost components in LOPD among patients receiving supportive care were home care (31\%), informal care (26\%), and productivity losses (12\%).

Resource use among LOPD patients was generally high, including both inpatient and outpatient visits, physicians, physical therapy, occupational therapists, social workers, nursing homes, ambulation devices, and respiratory support. Nursing home admissions accounted for $19 \%$ of the total $€ 13,679$ annual medical costs, while respiratory support accounted for only €574 per patient annually [31]. It is important to note that LOPD is, phenotypically, extremely heterogeneous, with ages of onset ranging from 12 months to late adulthood. Patients who have survived to adulthood without receiving treatment are likely to be those on the milder end of the spectrum and, as such, may require less care and medical intervention than those patients with more severe forms of the disease. These results should, therefore, be interpreted with caution when applying them to the Pompe disease population as a whole.

Despite these caveats, it was reported that among LOPD patients treated with ERT, the estimated mean annual cost of caring for patients, excluding the costs of ERT, was only $£ 6300$ ( $\$ 8989$ ) [35]. This is substantially less than the $€ 22,475$ ( $\$ 28,489)$ reported by Kanters et al. (2011) [31], although Wyatt et al. did not include costs associated with informal care and productivity losses, which were the two major components in the latter publication.

Of note, this review also reveals that costs and resource use were significantly higher and health utilities were lower for both ERT-treated and non-treated LOPD patients using ambulatory or respiratory devices compared with patients not requiring these devices [31,32]. This finding is not surprising given the greater costs associated with wheelchair use and respiratory devices in other conditions [41, 42] and the fact that their use indicates greater disease severity and progression. Furthermore, utility scores were lower among LOPD patients requiring ambulatory support compared with those using ventilator support, suggesting that the need for ambulatory support has a greater impact on the ability to lead a normal life and that these patients may require more caregiver support. 
In terms of indirect costs, Kanters et al. (2011) reported that $85 \%$ of patients received informal care, and also found a considerable impact of Pompe disease on productivity [31]. In their study of untreated adult patients with LOPD, only $39 \%$ of patients were employed, with $40 \%$ indicating that they had stopped working due to Pompe disease. Of those who worked, $32 \%$ were reported absent from work due to illness for an average of 12 work days per year, $52 \%$ said they worked an average of $14 \mathrm{~h}$ a week less than they would without Pompe disease, and 19\% would have applied for a job at a higher functional level if they had not been affected by the disease. Productivity losses due to Pompe disease were estimated to account for $12 \%$ of total annual diseaserelated costs.

Finally, the costs of treating Pompe disease patients with ERT are vast (Figs. 2 and 3). For example, at £6300 (\$8989), the annual cost of caring for adults with LOPD in the UK (excluding the purchase cost of ERT) is dwarfed by the mean annual cost of ERT, estimated at $£ 282,798$ (\$403,490) [35]. This was consistent across studies and countries, with adjusted annual costs of ERT for adults estimated at $\$ 503,118$ (Canada [33]) and \$547,835 (US [34]). In IOPD, the lifetime incremental costs associated with ERT use are estimated to be $€ 7.0$ million $(\$ 8,873,238)$, with the majority $(95 \%)$ of the incremental costs due to ERT itself, followed by infusion costs [30]. Since some IOPD patients are now treated with higher doses $(40 \mathrm{mg} / \mathrm{kg}$ biweekly or even weekly) than initially recommended ( $20 \mathrm{mg} / \mathrm{kg}$ biweekly) [43], this adds considerably to the cost burden. It is important to note, however, that the considerable incremental lifetime costs in ERT-treated IOPD patients are not simply due to the ERT treatment itself, but also because of the substantially longer life expectancy of ERT-treated patients (around 14 years) compared with those managed with supportive care only (a few months only) [30].

ICERs, defined as the incremental costs per QALY gained at the $20 \mathrm{mg} / \mathrm{kg}$ biweekly dose, ranged from $£ 109,991$ (\$186,851) for Colombia [29] to $£ 234,308(\$ 347,070)$ for England [29] and $€ 286,114(\$ 362,678)$ for the Netherlands [30]. At a dosage of $40 \mathrm{mg} / \mathrm{kg} /$ week, the ICER was $€ 1,043,868(\$ 1,323,207)$ [30]. Thus, while there are large differences reported across different countries and healthcare systems, the ICER for ERT in IOPD is consistently high when compared with some established cost-effectiveness thresholds.

\subsection{Gaps and Limitations of this Review}

Despite a full systematic literature search, only eight publications were found reporting on the health economic evidence of Pompe disease (four in LOPD, two in IOPD and two in both LOPD and IOPD). The most robust evidence for IOPD, from two of four publications, is focused on cost-effectiveness evaluations [29, 34]. The two other studies that included IOPD patients in the US [34] and England [35] specifically focus on drug costs only for ERT. The US study only focuses on the total budget impact, but calculated per prescription and not per patient cost. In terms of LOPD data, three of the six main studies come from the same source data (the IPA/Erasmus Medical Center Pompe Survey) [31, 32, 36], and include both analyses of ERT and non-ERT treatment populations as well as combined evaluations. A fourth LOPD study also focuses solely on drug costs per patient and lacks transparency, in that it is the application of a policy framework for rare disease therapy coverage decisions. Furthermore, that study focused only on cost per patient and budget impact [33].

This review reveals a substantial gap in health economic evidence relating to Pompe disease in countries beyond the Netherlands and England. In addition, the available evidence is mixed, as many of the cost studies specifically exclude a cost-effectiveness analysis due to the paucity of data and the expectation that cost-effectiveness analysis ratios would be extremely high and not informative. Indeed, where costeffectiveness analyses were performed by Kanters et al. in multiple publications, the models do produce ICERs well above the willingness-to-pay thresholds. It should be noted that disregarding discounting in cost-effectiveness analyses may result in an underestimation of treatment costs, particularly given the lifetime time horizon. Furthermore, the models used vary in assumptions and inputs, requiring caution when comparing results across models and countries. The models are primarily driven by the ERT costs, and assumptions of the impact of ERT on survival vary among models, affecting health utilities adjustments for ERT versus non-ERT-treated patients. Although additional information may be available on the costs and cost-effectiveness in reimbursement decisions around the world, these sources fall outside the inclusion criteria for our review as they are largely non-peer reviewed. As described in Sect. 2.2, our review was restricted to peer-reviewed articles describing cohort, cross-sectional, case-control studies and randomized controlled trials.

For IOPD, there is a complete absence of published data on the indirect economic burden, health utilities and clinical drivers of cost and resource use, meaning that it was not possible to create a complete picture of the economic burden of IOPD. To partially address this gap, further insights can be taken from the published literature on a comparable disease such as spinal muscular atrophy (SMA). For example, one 2016 study reported an average cost of illness of SMA patients in Germany of $€ 70,566 /$ year per patient, consisting of $€ 14,342 /$ year per patient in direct medical costs $(20 \%$ of the overall cost of illness), €40,378/year in direct nonmedical costs $(58 \%)$ and $€ 15,845 /$ year in total indirect costs $(22 \%)$ [44]. 
For LOPD, data on untreated patients receiving supportive care only are drawn from a single study, and for those treated with ERT, only one study was entirely prospective, meaning that there were limitations to the information that was available and the conclusions that could be drawn. There were no data on indirect economic burden in LOPD in the post-ERT setting, while there were only limited data correlating disease progression with poor health utilities and higher costs or resource use following ERT. Additionally, due to the small sample size, no meta-analysis was possible. As such, there are limitations to the conclusions that can be drawn from this systematic review.

Other limitations derive from the nature of the studies reported. Most of the studies included have been rated on the Newcastle-Ottawa Scale as being of relatively poor quality (scoring 2-5 out of a maximum of 9). The low scores reflect deficiencies in the studies in terms of selection of cohorts, comparability of cohorts, and assessment of outcome. For example, patients who had survived for any length of time on supportive care only are likely to have been on the mild end of the disease spectrum, and may not be truly reflective of the wider patient population. Similarly, milder patients are less likely to receive respiratory or ambulatory support, and thus including them in analyses of healthcare resource use may underrepresent the total cost for the overall patient population. Another consideration is the impact of the weight of patients (particularly children, which may vary widely) on treatment costs, such that each study that uses different weights will have different treatment costs per patient. Data were adjusted to a standard dosing and frequency factor, but this adjustment does not take into account patient weight. Therefore, the average cost of a pediatric patient will be much lower than that of an adult, despite the same dosing regimen.

Like most other systematic reviews of the literature, this review suffers from potential publication bias. In general, this bias exists because studies that report positive associations are more likely to be published. Therefore, it is possible that studies containing valuable data may have gone undetected. Since we restricted this systematic review to studies published in English, it is possible that language bias may have affected our conclusions. Despite these limitations, we believe that the available literature reviewed here demonstrates the paucity of data in this area and the substantial cost associated with Pompe disease.

\subsubsection{Avenues for Future Research}

This systematic review highlights the relative lack of consistent, validated data evaluating the health economics of Pompe disease. As new therapeutic approaches become available, it will be increasingly important, in addition to the clinical relevance of a new drug, to accurately assess the true economic burden and health economic value of treating both LOPD and IOPD.

One important avenue of research will be to consider how clinical progression impacts the economic burden of Pompe disease in terms of costs, resource use, and health utilities. Previous studies have demonstrated continued disease progression despite ERT therapy [19-21, 45, 46], and it is therefore important that this effect be captured in future economic models. Another important research question that has not been addressed to date relates to the impact of ERT on the indirect economic burden and health utilities in Pompe disease. Until a quantitative evaluation of the change in indirect economic burden and health utilities following the advent of ERT for the treatment of Pompe disease is realized, our understanding of the overall economic burden of ERT-treated patients will remain incomplete.

\section{Conclusions}

Here, we present the first systematic review of the health economics of Pompe disease. This adds to other literature describing the significant clinical and humanistic burden Pompe disease presents. While there remain substantial gaps in the published literature, available data demonstrate that there is a high, persistent cost to patients, families, healthcare systems, and society in the presence and absence of ERT. Further research is needed to fully understand the complete picture across the spectrum of the disease, but it is clear that there remains a substantial cost associated with Pompe disease that is not fully addressed with existing treatment paradigms.

Acknowledgments The authors would like to thank Rachel Danks for assistance with the preparation of this manuscript.

Availability of Data and Materials All data used in this literature review are derived from published studies and are thus already available.

Authors' Contributions BS, EJ and SP contributed to the conception and design of the study. DG designed and carried out the search strategies. All authors were responsible for acquisition, analysis and interpretation of data. All authors drafted the manuscript. All authors read, critically revised and approved the final manuscript.

\section{Compliance with Ethical Standards}

Funding The literature review and editorial assistance for the manuscript was funded by Audentes Therapeutics.

Conflict of interest BS is a member of the Audentes Therapeutics Board of Scientific and Clinical Advisors. BS has received unrestricted research support, honoraria, and travel funding from Sanofi Genzyme during the past 5 years. BS received honoraria and travel funding as a member of the Global Advisory Boards from Biomarin Pharmaceutical, Lupin therapeutics, Nexien biopharm, Amicus Therapeutics, and 
Audentes Therapeutics. EJ and SP are employed by and own stock in Audentes Therapeutics, DG is a paid consultant of Audentes Therapeutics, and MG is an employee of BluePath Solutions, a company that receives consulting fees from Audentes Therapeutics. AH has no conflicts of interest.

\section{Ethics approval and consent to participate Not applicable.}

Consent for publication Not applicable.

Open Access This article is distributed under the terms of the Creative Commons Attribution-NonCommercial 4.0 International License (http://creativecommons.org/licenses/by-nc/4.0/), which permits any noncommercial use, distribution, and reproduction in any medium, provided you give appropriate credit to the original author(s) and the source, provide a link to the Creative Commons license, and indicate if changes were made.

\section{References}

1. National Center for Advancing Translational Sciences and Genetic and Rare Diseases Information Center. In: FAQs about rare diseases. 2016. https://rarediseases.info.nih.gov/diseases/pages/31/ faqs-about-rare-diseases. Accessed 14 Dec 2018.

2. Drummond MF, Wilson DA, Kanavos P, Ubel P, Rovira J. Assessing the economic challenges posed by orphan drugs. Int J Tech Ass Health Care. 2007;23:36-42.

3. López-Bastida J, Oliva-Moreno J. Cost of illness and economic evaluation in rare diseases. Adv Exp Med Biol. 2010;686:273-82.

4. Prasad S, James E. The challenges associated with developing therapies for rare diseases. Br J Med Pr. 2009;1:42-8.

5. Hirschhorn R, Reuser AJJ. Glycogen storage disease type II: acid $\alpha$-glucosidase (acid maltase) deficiency. In: Scriver CR, Beau$\operatorname{det}$ AL, Sly WS, Valle D, editors. The metabolic and molecular basis of inherited disease, vol. 3. 8th ed. New York: McGraw-Hill; 2001. p. 3389-420.

6. Bhengu L, Davidson A, du Toit P, Els C, Gerntholzt T, Govendrageloo K, et al. Diagnosis and management of Pompe disease. S Afr Med. 2014;104:273-4.

7. Chien Y-H, Hwu W-L, Lee N-C. Pompe disease: early diagnosis and early treatment make a difference. Pediatr Neonatol. 2013;54:219-27.

8. Schoser B, Stewart A, Kanters S, Hamed A, Jansen J, Chan K, et al. Survival and long-term outcomes in late-onset Pompe disease following alglucosidase alfa treatment: a systematic review and meta-analysis. J Neurol. 2017;264:621-30.

9. Ausems MG, Verbiest J, Hermans MP, Kroos MA, Beemer FA, Wokke JH, et al. Frequency of glycogen storage disease type II in the Netherlands: implications for diagnosis and genetic counselling. Eur J Hum Genet. 1999;7:713-6.

10. Lin CY, Hwang B, Hsiao KJ, Jin YR. Pompe's disease in Chinese and prenatal diagnosis by determination of alpha-glucosidase activity. J Inherit Metab Dis. 1987;10:11-7.

11. Bashan N, Potashnik R, Barash V, Gutman A, Moses SW. Glycogen storage disease type II in Israel. Isr J Med Sci. 1988;24:224-7.

12. National Institute of Neurological Disorders and Stroke. In: Pompe disease information page. https://www.ninds.nih.gov/Disor ders/All-Disorders/Pompe-Disease-Information-Page. Accessed 14 Dec 2018.

13. Cupler EJ, Berger KI, Leshner RT, Wolfe GI, Han JJ, Barohn RJ, et al. Consensus treatment recommendations for late onset Pompe disease. Muscle Nerve. 2012;45:319-33.
14. Sanofi Genzyme. In: Genzyme receives label expansion for Lumizyme $^{\circledR}$ (alglucosidase alfa) in the United States for the treatment of Pompe disease. 2014. http://news.genzyme.com/press -release/genzyme-receives-label-expansion-lumizyme-alglucosid ase-alfa-united-states-treatment-p. Accessed 14 Dec 2018.

15. Chakrapani A, Vellodi A, Robinson P, Jones S, Wraith JE. Treatment of infantile Pompe disease with alglucosidase alpha: the UK experience. J Inherit Metab Dis. 2010;33:747-50.

16. Hahn A, Praetorius S, Karabul N, Dießel J, Schmidt D, Motz R, et al. Outcome of patients with classical infantile Pompe disease receiving enzyme replacement therapy in Germany. JIMD Rep. 2015;20:65-75.

17. Broomfield A, Sweeney MG, Woodward CE, Fratter C, Morris AM, Leonard JV, et al. Paediatric single mitochondrial DNA deletion disorders: an overlapping spectrum of disease. J Inherit Metab Dis. 2015;38:445-57.

18. Kishnani PS, Corzo D, Leslie ND, Gruskin D, van der Ploeg A, Clancy JP, et al. Early treatment with alglucosidase alpha prolongs long-term survival of infants with Pompe disease. Pediatr Res. 2009;66:329-35.

19. Güngör D, Kruijshaar ME, Plug I, Rizopoulos D, Kanters TA, Wens SC, et al. Quality of life and participation in daily life of adults with Pompe disease receiving enzyme replacement therapy: 10 years of international follow-up. J Inherit Metab Dis. 2016;39:253-60.

20. Van der Ploeg AT, Clemens PR, Corzo D, Escolar DM, Florence $\mathbf{J}$, Groenveld GJ, et al. A randomized study of alglucosidase alfa in late-onset Pompe's disease. N Engl J Med. 2010;362:1396-406.

21. Güngör D, Schober AK, Kruijshaar ME, Plug I, Karabul N, Deschauer M, et al. Pain in adult patients with Pompe disease: a cross-sectional survey. Mol Genet Metab. 2013;109:371-6.

22. Angelini $C$, Semplicini $C$, Tonin $P$, Filosto $M$, Pegoraro $E$, Sorarù $\mathrm{G}$, et al. Progress in enzyme replacement therapy in glycogen storage disease type II. Ther Adv Neurol Disord. 2009;2:143-53.

23. Strothotte S, Strigl-Pill N, Grunert B, Kornblum C, Eger K, Wessig C, et al. Enzyme replacement therapy with alglucosidase alfa in 44 patients with late-onset glycogen storage disease type 2: 12-month results of an observational clinical trial. J Neurol. 2010;257:91-7.

24. Regnery C, Kornblum C, Hanisch F, Vielhaber S, Strigl-Pill N, Grunert B, et al. 36 months observational clinical study of 38 adult Pompe disease patients under alglucosidase alfa enzyme replacement therapy. J Inherit Metab Dis. 2012;35:837-45.

25. Schoser B, Bilder DA, Dimmock D, Gupta D, James ES, Prasad $\mathrm{S}$. The humanistic burden of Pompe disease: are there still unmet needs? A systematic review. BMC Neurol. 2017;17(1):202.

26. Dasouki M, Jawdat M, Almadhoun O, Pasnnor M, McVey AL, Abuzinadah A, et al. Pompe disease: literature review and case series. Neurol Clin. 2014;32:751-76.

27. Moher D, Liberati A, Tetzlaff J, Altman DG, PRISMA Group. Preferred reporting items for systematic reviews and meta-analyses: the PRISMA statement. PLoS Med. 2009;6:e1000097.

28. Wells G, Shea B, O'Connell D, Peterson J, Welch V, Losos M et al. In: The Newcastle-Ottawa Scale (NOS) for assessing the quality of nonrandomised studies in meta-analyses. 2013. http:// www.ohri.ca/programs/clinical_epidemiology/oxford.asp. Accessed 14 Dec 2018.

29. Castro-Jaramillo HE. The cost-effectiveness of enzyme replacement therapy (ERT) for the infantile form of Pompe disease: comparing a high-income country's approach (England) to that of a middle income one (Colombia). Rev Salud Publica. 2012;14:143-55.

30. Kanters TA, Hoogenboom-Plug I, Rutten-Van Mölken MP, Redekop WK, Van Der Ploeg AT, Hakkaart L. Cost-effectiveness of enzyme replacement therapy with alglucosidase alfa in 
classic-infantile patients with Pompe disease. Orphanet J Rare Dis. 2014;9:75.

31. Kanters TA, Hagemans MLC, Van Der Beek NAME, Rutten FFH, Van Der Ploeg AT, Hakkaart L. Burden of illness of Pompe disease in patients only receiving supportive care. J Inherit Metab Dis. 2011;34:1045-52.

32. Kanters TA, Redekop WK, Kruijshaar ME, Van Der Ploeg AT, Rutten-Van MÃlken MPMH, Hakkaart L. Comparison of EQ-5D and SF-6D utilities in Pompe disease. Qual Life Res. 2015;24:837-44.

33. Winquist E, Coyle D, Clarke JTR, Evans GA, Seager C, Chan $\mathrm{W}$, et al. Application of a policy framework for the public funding of drugs for rare diseases. J Gen Intern Med. 2014;29(Suppl. 3):S774-9.

34. Guo J, Kelton CML, Guo JJ. Recent developments, utilization, and spending trends for Pompe disease therapies. Am Health Drug Benefits. 2012;5:182-9.

35. Wyatt K, Henley W, Anderson L, Anderson R, Nikolaou V, Stein $\mathrm{K}$, et al. The effectiveness and cost-effectiveness of enzyme and substrate replacement therapies: a longitudinal cohort study of people with lysosomal storage disorders. Health Technol Assess. 2012;16:1-566.

36. Kanters TA, van der Ploeg AT, Kruijshaar ME, Rizopoulos D, Redekop WK, Rutten-van Mölken MPMH, et al. Cost-effectiveness of enzyme replacement therapy with alglucosidase alfa in adult patients with Pompe disease. Orphanet J Rare Dis. 2017; $12: 179$.

37. Nanavaty M, Kaura S, Mwamburi M, Gogate A, Proach J, Nyandege A, et al. The use of incremental cost-effectiveness ratio thresholds in health technology assessment decisions. J Clin Pathway. 2015;1:29-36.

38. Dakin H, Devlin N, Feng Y, Rice N, O'Neill P, Parkin D. The influence of cost-effectiveness and other factors on NICE decisions. Health Econ. 2015;24:1256-71.
39. Bae YHJ, Mullins CD. Do value thresholds for oncology drugs differ from nononcology drugs? J Manag Care Pharm. 2014;20:1086-92.

40. Stolk EA, Krabbe P, Busschbach J. Using the internet to collect EQ-5D norm scores: a valid alternative? In: Busschbach J, Rabin R, De Charro F, editors. In: Proceedings of the 24th scientific plenary meeting of the EuroQol Group. Kijkduin-The Hague, the Netherlands, September 13-15, 2007. EuroQol Group, Rotterdam; 2009, pp. 153-165.

41. Larkindale J, Yang W, Hogan PF, Simon CJ, Zhang Y, Jain A, et al. Cost of illness for neuromuscular diseases in the United States. Muscle Nerve. 2014;49:431-8.

42. American Diabetes Association. Economic costs of diabetes in the U.S. in 2007. Diabetes Care. 2008;31:596-615.

43. van Gelder CM, Poelman E, Plug I, Hoogeveen-Westerveld M, van der Beek NA, Reuser AJ, et al. Effects of a higher dose of alglucosidase alfa on ventilator-free survival and motor outcome in classic infantile Pompe disease: an open-label single-center study. J Inherit Metab Dis. 2016;39:383-90.

44. Klug C, Schreiber-Katz O, Thiele S, Schorling E, Zowe J, Reilich $\mathrm{P}$, et al. Disease burden of spinal muscular atrophy in Germany. Orphanet J Rare Dis. 2016;11:58.

45. Ebbink BJ, Poelman E, Aarsen FK, Plug I, Régal L, Muentjes C, et al. Classic infantile Pompe patients approaching adulthood: a cohort study on consequences for the brain. Dev Med Child Neurol. 2018;60:579-86.

46. Schoser B. Novel Pompe disease phenotype: a treatment-related modified phenotype neglecting the brain. Dev Med Child Neurol. 2018;60:536. 